\title{
On the Optimal Glass-Forming Composition of Al-Co-Y Amorphous Alloys
}

\author{
Xianzhong Xiong ${ }^{1}$, Jiaojiao $\mathrm{Yi}^{1}$, Lingti Kong ${ }^{1}$, Michael Ferry ${ }^{2}$, Jinfu $\mathrm{Li}^{1, *}$ and Yaohe Zhou ${ }^{1}$ \\ ${ }^{1}$ State Key Laboratory of Metal Matrix Composites, and Shanghai Key Laboratory of Materials Laser Processing and Modification, \\ School of Materials Science and Engineering, Shanghai Jiao Tong University, Shanghai 200240, China \\ ${ }^{2}$ School of Materials Science and Engineering, The University of New South Wales, Sydney, NSW 2052, Australia
}

\begin{abstract}
Al-Co-Y alloys were suction cast under identical conditions into a wedge-shaped copper mold for investigating the compositional dependence of glass-forming ability (GFA). The optimal glass-forming composition was determined to be $\mathrm{Al}_{89} \mathrm{Co}_{5.5} \mathrm{Y}_{5.5}$, whose $\mathrm{Al}$ content is evidently larger than the findings of the optimal glass formers in other Al-TM-Y alloy systems. A reason is that Co-centered clusters tend to share vertexes and edges rather than faces with the surrounding clusters in Al-Co-Y amorphous alloy, and more Al atoms are required. When $\mathrm{Al}_{89} \mathrm{Co}_{5.5} \mathrm{Y}_{5.5}$ amorphous alloy and its neighbors were isochronally annealed in a differential scanning calorimeter, no glass transition could be observed and the primary crystallization phase was invariably fcc-Al. [doi:10.2320/matertrans.M2018177]
\end{abstract}

(Received May 30, 2018; Accepted July 19, 2018; Published September 25, 2018)

Keywords: Al alloy, glass forming ability, microstructure, crystallization behavior

\section{Introduction}

Since the successful preparation of ductile Al-based amorphous alloys by Inoue and He et al. in 1988, ${ }^{1,2)} \mathrm{Al}-$ based amorphous alloys have been drawing worldwide attention due to their high specific strength and good ductility. ${ }^{3)}$ Compared with other amorphous alloys, Albased amorphous alloys show some distinctive features. For instance, the content of $\mathrm{Al}$ atoms exceeds 80 at $\%$, being extraordinarily high even as the main element; ${ }^{3}$ the best glass-forming compositions are far off eutectic points for many binary and ternary Al-based alloy systems; and the glass-forming ability (GFA) is very sensitive to the alloy composition. $^{4-10)}$ Following the empirical rule that similar element substitution often have a positive effect on GFA, ${ }^{11)}$ Wang et al. ${ }^{12-15)}$ prepared Al-based bulk amorphous alloys of $1 \mathrm{~mm}$ diameter from $\mathrm{Al}_{86} \mathrm{Ni}_{6} \mathrm{Y}_{4.5} \mathrm{Co}_{2} \mathrm{La}_{1.5}, \mathrm{Al}_{86} \mathrm{Ni}_{7} \mathrm{Y}_{5} \mathrm{Co}_{1} \mathrm{La}_{1}$ and $\mathrm{Al}_{86} \mathrm{Ni}_{7} \mathrm{Y}_{4.5} \mathrm{Co}_{1} \mathrm{La}_{1.5}$ and $1.5 \mathrm{~mm}$ diameter from $\mathrm{Al}_{86}-$ $\mathrm{Ni}_{6.75} \mathrm{Co}_{2.25} \mathrm{Y}_{3.25} \mathrm{La}_{1.75}$ and $\mathrm{Al}_{86} \mathrm{Ni}_{6} \mathrm{Y}_{4.5} \mathrm{Co}_{2} \mathrm{La}_{1.5}$. Even so, the Al-based amorphous samples obtained are still much smaller than the Zr-, Pd-, Fe- and Cu-based amorphous alloys. ${ }^{16-18)}$

The ability for an alloy to form a glass is equivalent to suppressing crystallization within the undercooled liquid. An alloy melt whose atoms are densely packed is known to be sluggish in crystallization kinetics. The efficient atomic packing (EAP) model was therefore proposed by Miracle et al. ${ }^{19)}$ to design amorphous alloys. For Al-based amorphous alloys, the solute atoms are exclusively surrounded by $\mathrm{Al}$ atoms owing to the strong chemical bonding between the $\mathrm{Al}$ and solute atoms ${ }^{4}$ and the high content ratios of the Al to the solute. Sheng et al. ${ }^{4}$ computer simulated the threedimensional atomic configurations of numerous Al-based amorphous alloys, and gave the average coordination number of $\mathrm{Al}$ atoms for various solute atoms. With the above advances, Ma et al. ${ }^{20)}$ proposed a cluster stability line intersection (CSLI) method to search the composition with the best GFA in ternary Al-based alloys. Zhang et al. ${ }^{9,21)}$ later modified this method by taking the effect of interaction between different elements on atomic radii into account. The

*Corresponding author, E-mail: jfli@sjtu.edu.cn optimal glass-forming compositions of several Al-Ni-RE ternary systems were predicted to be $\mathrm{Al}_{85.7} \mathrm{Ni}_{9.5} \mathrm{La}_{4.8}$ and $\mathrm{Al}_{85.5} \mathrm{Ni}_{9.5} \mathrm{RE}_{5}$ ( $\left.\mathrm{RE}=\mathrm{Y}, \mathrm{Ce}, \mathrm{Gd}, \mathrm{Dy}\right)$, in good agreement with the experimental results. ${ }^{9)}$

$\mathrm{Co}$ and $\mathrm{Ni}$ are similar to each other in the physical and chemical properties. The optimal glass-forming composition of $\mathrm{Al}-\mathrm{Co}-\mathrm{Y}$ calculated by the EAP model in combination with the CSLI method is $\mathrm{Al}_{85.5} \mathrm{Co}_{9.5} \mathrm{Y}_{5.0}$ (the derivation is shown below). The atomic ratio among the three elements is very close to the value of the optimal glass-forming composition of $\mathrm{Al}-\mathrm{Ni}-\mathrm{Y}$. On the other hand, the optimal glass former in Al-Co-RE was experimentally determined by Yang et al. ${ }^{22)}$ to be $\mathrm{Al}_{89} \mathrm{Co}_{6} \mathrm{RE}_{5}$ and $\mathrm{Al}_{90} \mathrm{Co}_{6} \mathrm{RE}_{4}$, and by Dong et al. ${ }^{23)}$ to be $\mathrm{Al}_{88} \mathrm{Co}_{5} \mathrm{Y}_{7}$. In the present work, we first examined the GFA of Al-Co-Y alloys in a wide composition range by carefully controlling the preparation condition. Then theoretical analyses were made to unravel what results in the high $\mathrm{Al}$ content in the optimal glass-forming compositions of Al-Ni-Y.

\section{Experimental Procedure}

The Al-Co-Y alloys investigated in this work are shown in Fig. 1. The alloy compositions distribute in two separate regions: one around the optimal composition predicted by the CSLI method, where two lines represent the content ratios of $\mathrm{Al} / \mathrm{Y}$ and $\mathrm{Al} / \mathrm{Co}$; the other covering the compositions of $\mathrm{Al}_{88} \mathrm{Co}_{5} \mathrm{Y}_{7}, \mathrm{Al}_{89} \mathrm{Co}_{6} \mathrm{Y}_{5}$ and $\mathrm{Al}_{90} \mathrm{Co}_{6} \mathrm{Y}_{4}$. Alloy ingots were prepared by arc melting the mixture of $\mathrm{Al}$ (99.999\%), Co (99.99\%) and Y (99.9\%) in a water-cooled copper crucible under the Ti-gettered argon atmosphere. All the ingots were melted six times to ensure their compositional homogenization. The oxides on the as-prepared ingots were eliminated before the ingots were cut into small pieces weighing about 2 grams. Each piece of the alloy ingots was remelted and suction cast into a copper mould with an included angle of 5 degrees and a width of $10 \mathrm{~mm}$ to form a wedge-shaped sample in the arc melting furnace. The arc current and melting duration were controlled to be the same for all the casting operations. At least two wedge-shaped samples were prepared for each alloy composition to make 


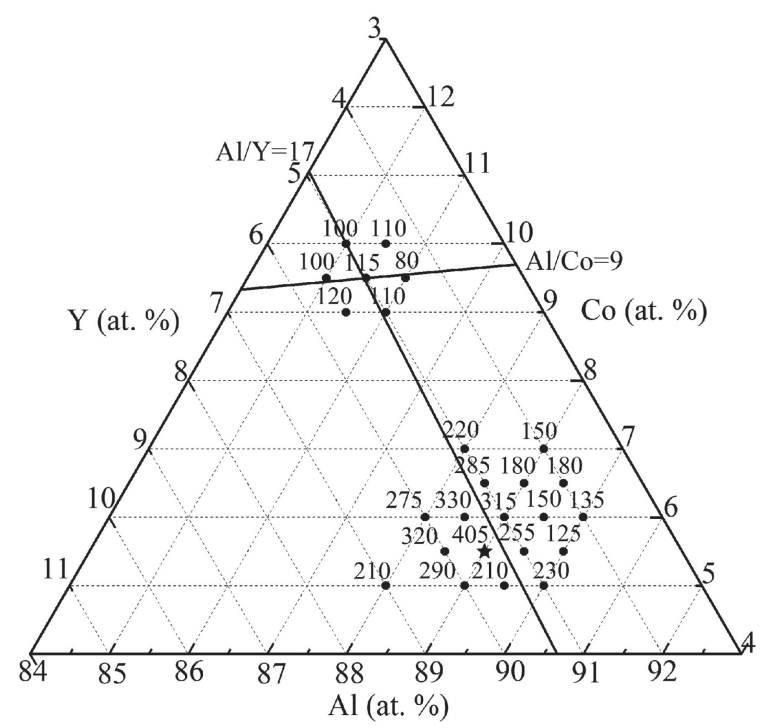

Fig. 1 Al-Co-Y compositions investigated and corresponding critical thickness $t_{\mathrm{c}}(\mu \mathrm{m})$ of amorphous region in the wedge-shaped Al-Co-Y samples, where two straight lines $(\mathrm{Al} / \mathrm{Y}=17$ and $\mathrm{Al} / \mathrm{Co}=9)$ represent the cluster stability lines.

sure that the results would be reliable. The as-cast wedgeshaped samples were then cut into two parts using a diamond saw along the central section and perpendicular to the inclined planes. After that, the samples were carefully mounted, polished, and etched using the Keller's reagent. The maximum thickness of the amorphous region was measured using an optical microscope as an indicator of GFA. To check the amorphous nature of the tip region, a JOEL JEM-2100F high-resolution transmission electron microscope (HRTEM) was used to examine the foils prepared by twin-jet polishing in a solution of $25 \% \mathrm{HNO}_{3}$ and $75 \%$ methanol at $233 \mathrm{~K}$.

To study the crystallization behavior of the Al-Co-Y amorphous alloys, ribbons of $20-30 \mu \mathrm{m}$ thickness and $5 \mathrm{~mm}$ width were spun at a copper-wheel surface velocity of $40 \mathrm{~m} / \mathrm{s}$ in a vacuum single roller melt-spinning apparatus. After their amorphous nature was identified by X-ray diffraction (XRD) with $\mathrm{Cu} \mathrm{K} \alpha$ radiation, the ribbons were annealed in a Perkin Elmer Pyris Diamond differential scanning calorimeter (DSC) at a heating rate of $20 \mathrm{~K} / \mathrm{min}$ under a flow of highly-purified argon atmosphere to detect the crystallization. The ribbons annealed to the end of the first crystallization peak were also examined by XRD to determine the primary phase.

\section{Results}

\subsection{GFA}

An optical micrograph of the cross-section of an $\mathrm{Al}_{89} \mathrm{Co}_{5.5} \mathrm{Y}_{5.5}$ wedge-shaped sample is shown in Fig. 2. Two distinct regions representing the amorphous and crystalline parts respectively are observed. The HRTEM image and the selected area electron diffraction (SAED) pattern of the amorphous part are shown in Fig. 3. No visible crystals in the HRTEM image and the broad halo in the SAED pattern confirm the fully amorphous nature of the sample tip. Thus, it was reliable to use the average maximum thickness (critical thickness) $t_{\mathrm{c}}$ of the amorphous parts produced from the same alloy as the GFA indicator of the alloy.

All the $t_{\mathrm{c}}$ of the investigated Al-Co-Y alloys is marked in Fig. 1. The error of the measurements is within $10 \mu \mathrm{m}$. It can be seen that $t_{\mathrm{c}}$ is very sensitive to the alloy composition. Among all the alloys investigated, $\mathrm{Al}_{89} \mathrm{Co}_{5.5} \mathrm{Y}_{5.5}$ exhibits the best GFA, and its $t_{\mathrm{c}}$ is up to $405 \mu \mathrm{m}$. It is clear that $\mathrm{Al}_{89} \mathrm{Co}_{6} \mathrm{Y}_{5}, \mathrm{Al}_{90} \mathrm{Co}_{6} \mathrm{Y}_{4}$ and $\mathrm{Al}_{88} \mathrm{Co}_{5} \mathrm{Y}_{7}$ that were declared by some researchers ${ }^{20,21)}$ to have the best GFA present far smaller $t_{\mathrm{c}}$. With a no more than $120 \mu \mathrm{m} t_{\mathrm{c}}$, the alloys around $\mathrm{Al}_{85.5} \mathrm{Co}_{9.5} \mathrm{Y}_{5}$ exhibit worse GFA.

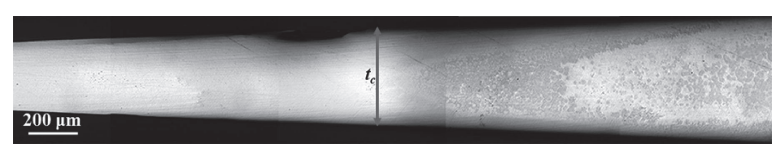

Fig. 2 Optical micrograph of a sectioned $\mathrm{Al}_{89} \mathrm{Co}_{5.5} \mathrm{Y}_{5.5}$ wedge-shaped sample.
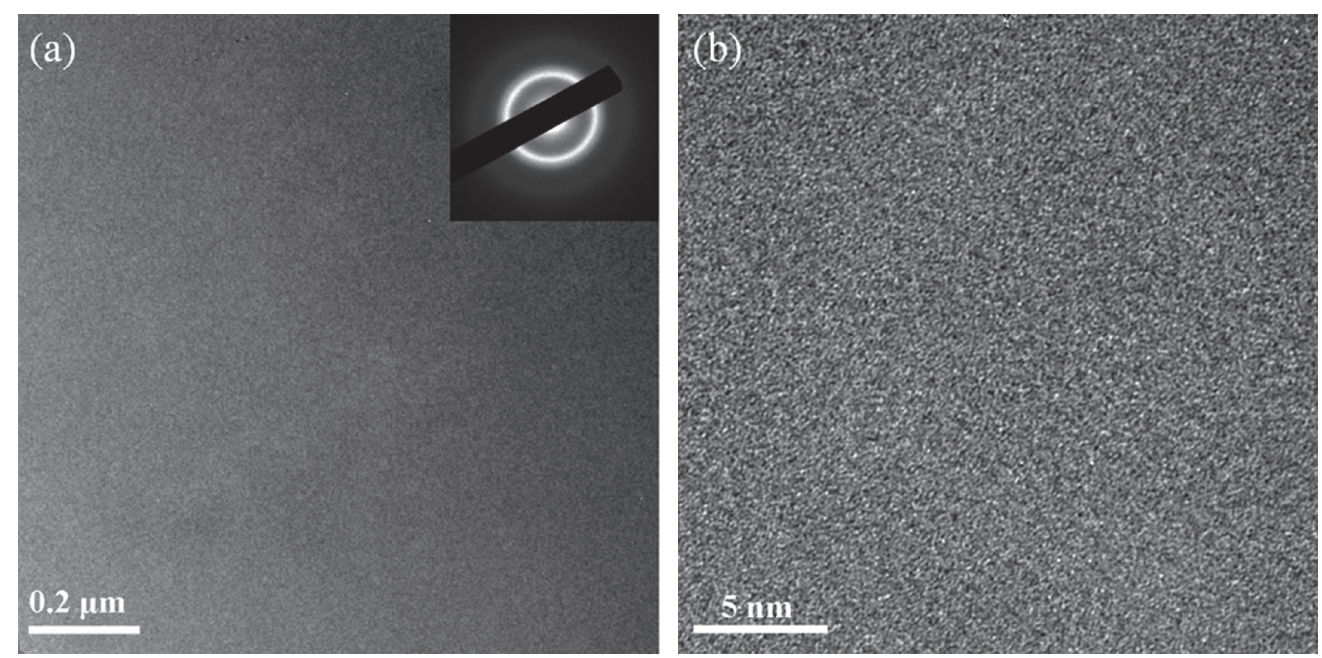

Fig. 3 (a) TEM bright-field image and SAED pattern of the amorphous part of an $\mathrm{Al}_{89} \mathrm{Co}_{5.5} \mathrm{Y}_{5.5}$ wedge-shaped sample and (b) the corresponding HRTEM image. 

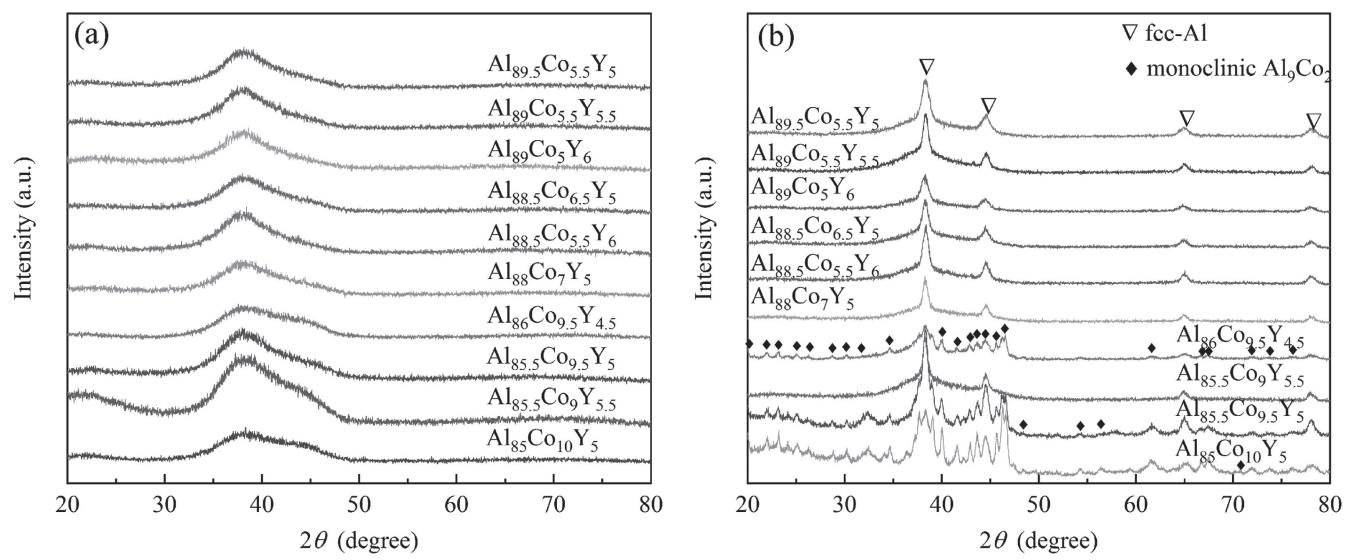

Fig. 4 XRD patterns of Al-Co-Y ribbons: (a) as-prepared, (b) annealed up to the end of the first exothermic peak respectively at a rate of $20 \mathrm{~K} / \mathrm{min}$.

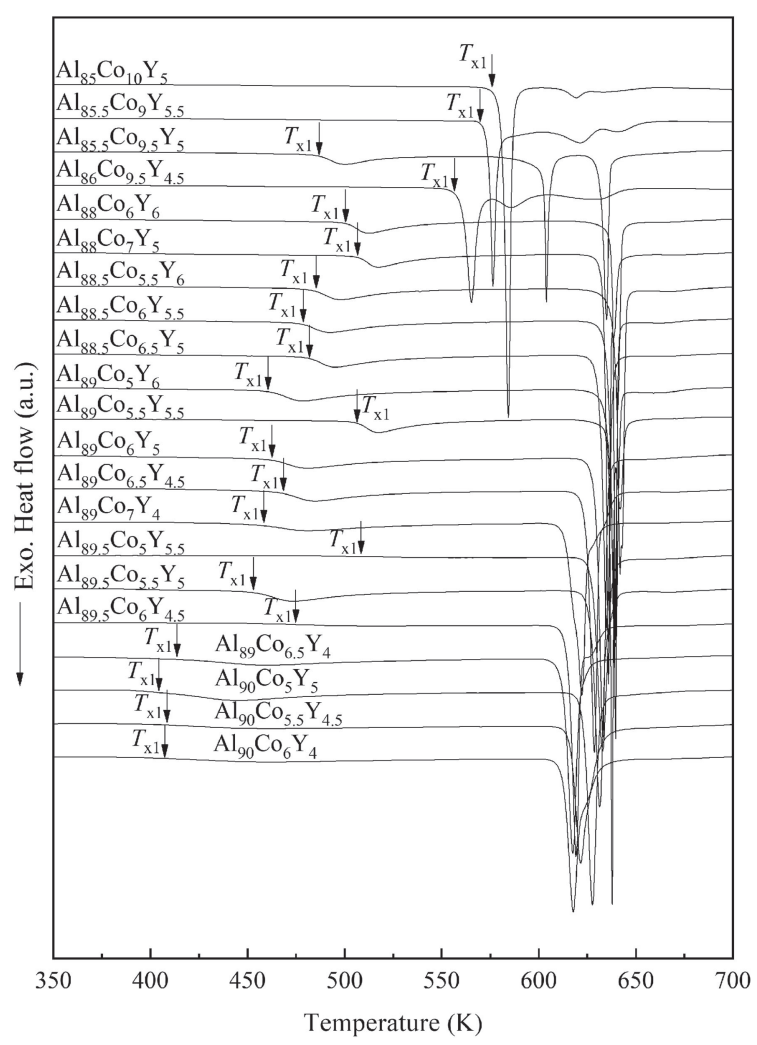

Fig. 5 DSC curves of the Al-Co-Y amorphous alloys at a heating rate of $20 \mathrm{~K} / \mathrm{min}$.

\subsection{Crystallization behavior}

Typical XRD patterns of the as-prepared Al-Co-Y ribbons are shown in Fig. 4(a). There are only broad peaks reflecting amorphous nature to be observed. The DSC curves of the ribbons at a heating rate of $20 \mathrm{~K} / \mathrm{min}$ are shown in Fig. 5 . No endothermic event took place before crystallization for all the Al-Co-Y amorphous alloys, indicating that no distinct glass transition was involved. Each DSC curve consists of at least two exothermic peaks. In general, the onset temperature of crystallization $T_{\mathrm{x} 1}$ decreases with increasing $\mathrm{Al}$ content. The XRD patterns of the Al-Co-Y ribbons annealed to the end of the first crystallization peak are shown in Fig. 4(b).
Except for some alloys surrounding $\mathrm{Al}_{85.5} \mathrm{Co}_{9.5} \mathrm{Y}_{5.0}$, the primary phase is composed of only fcc-Al for the other alloys.

\section{Discussions}

Metallic glass forms when crystallization does not occur during cooling of a molten metal to below the glass transition temperature $T_{\mathrm{g}}$. Some researchers therefore take glass formation as a result of competition with crystallization during the cooling process. ${ }^{24)}$ For the good glass formers, their compositions should be different from the composition of the primary crystallization phase so that the crystallization is easy to be hindered because of the necessary long-range solute diffusion. In general, more than one phases involve in the crystallization of a given alloy system, and obviously their compositions are different from each other. This is also the reason why the alloys with a near-eutectic composition have a good GFA. ${ }^{25-27)}$ Correspondingly, the optimal glassforming composition is often located at the boundary separating different sorts of primary crystallization phases in the composition triangle. ${ }^{9)}$ In the present work, however, the DSC and XRD results indicate that all the Al-Co-Y amorphous alloys around $\mathrm{Al}_{89} \mathrm{Co}_{5.5} \mathrm{Y}_{5.5}$ do not exhibit a glass transition during isochronal heat treatment, and the primary phase is constantly fcc-Al. That is to say, they all belong to the nanocrystalline alloys. ${ }^{28)}$ Therefore, it seems that the composition of the optimal glass former in Al-Co-Y does not further deviate from the composition of the primary phase.

According to the X-ray absorption fine structure (XAFS) analysis results of local atomic structures of Al-TM-RE amorphous alloys (TM-transition metals such as Fe, Co and $\mathrm{Ni}$, and RE-rare earth metals such as $\mathrm{La}, \mathrm{Ce}$ and $\mathrm{Y}$ ), the solute atoms are mostly surrounded by $\mathrm{Al}$ atoms. ${ }^{29,30)}$ The efficient atomic packing model proposed by Miracle et al. ${ }^{19)}$ can be used to describe the atomic arrangement in the good glass formers. Assuming that a solute atom is only surrounded by solvent atoms, there is the following relationship between the optimum coordination number $N^{\mathrm{T}}$ and $R$, the atomic radius ratio of the solute to solvent elements, ${ }^{19)}$ 

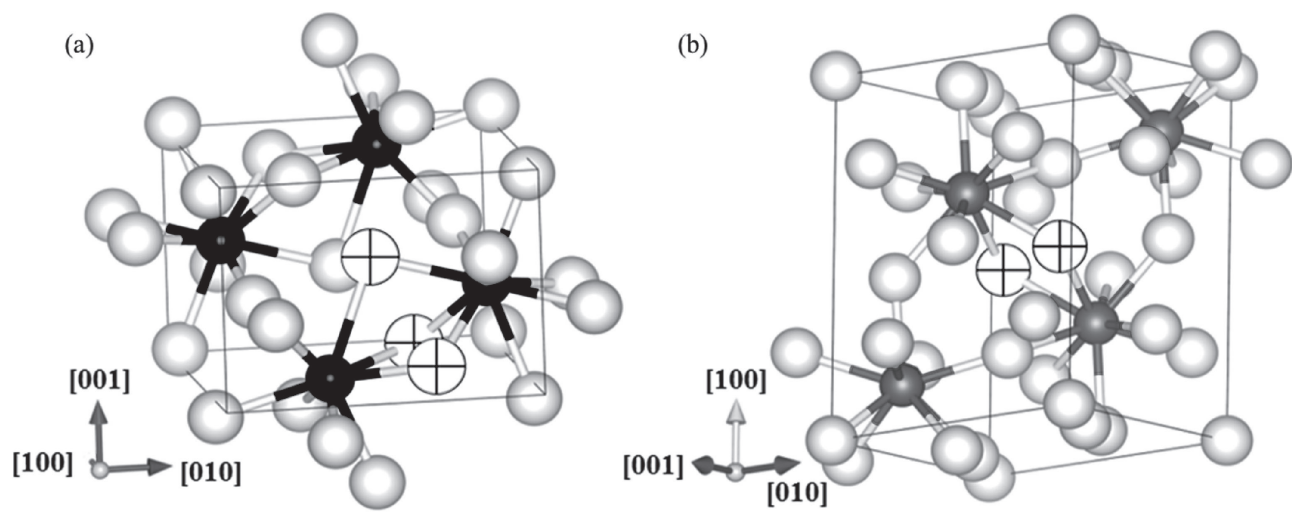

Fig. 6 Comparison of the TM-centered clusters in $\mathrm{Al}_{3} \mathrm{Ni}$ (a) and $\mathrm{Al}_{9} \mathrm{Co}_{2}$ (b). The black, dark grey and light grey atoms are nickel, cobalt and aluminum, respectively. The white atoms with a cross are aluminum shared by two clusters. Common face occurs in $\mathrm{Al}_{3} \mathrm{Ni}_{\mathrm{i}}$ while common edge occurs in $\mathrm{Al}_{9} \mathrm{Co}_{2}$.

$$
N^{\mathrm{T}}=\left\{\begin{array}{l}
\frac{4 \pi}{6 \arccos \left\{\sin (\pi / 3)\left[1-1 /(R+1)^{2}\right]^{1 / 2}\right\}-\pi} \\
\text { for } 0.225 \leq R \leq 0.414 \\
\frac{4 \pi}{8 \arccos \left\{\sin (\pi / 4)\left[1-1 /(R+1)^{2}\right]^{1 / 2}\right\}-2 \pi} \\
\begin{array}{c}
\text { for } 0.414 \leq R \leq 0.902 \\
\frac{4 \pi}{10 \arccos \left\{\sin (\pi / 5)\left[1-1 /(R+1)^{2}\right]^{1 / 2}\right\}-3 \pi} \\
\text { for } R \geq 0.902
\end{array}
\end{array}\right.
$$

In view of the fact that most Al-based amorphous alloys have three basic constituent elements, Ma et al. ${ }^{20)}$ developed the CSLI method to predict the optimum glass-forming compositions of Al-TM-RE metallic glasses. The expressions of the molar content of TM and RE given by them are as follows,

$$
\begin{aligned}
x_{\mathrm{TM}} & =\frac{1}{N_{\mathrm{TM}}^{\mathrm{T}} \times\left(1+1 / N_{\mathrm{TM}}^{\mathrm{T}}+1 / N_{\mathrm{RE}}^{\mathrm{T}}\right)} \\
x_{\mathrm{RE}} & =\frac{1}{N_{\mathrm{RE}}^{\mathrm{T}} \times\left(1+1 / N_{\mathrm{TM}}^{\mathrm{T}}+1 / N_{\mathrm{RE}}^{\mathrm{T}}\right)}
\end{aligned}
$$

where $N_{\mathrm{TM}}^{\mathrm{T}}$ and $N_{\mathrm{RE}}^{\mathrm{T}}$ are the optimum coordination numbers of TM and RE atoms, respectively. From the point of view of Wang et al., the TM and RE solute atoms should be uniformly dispersed among the Al base atoms, and do not contact directly. Meanwhile, each $\mathrm{Al}$ atom needs to be shared by two neighboring solute-centered clusters. Considering that the Al-TM bond length is obviously smaller than the sum of the nominal atomic radii of $\mathrm{Al}$ and $\mathrm{TM}$ in $\mathrm{Al}-\mathrm{TM}-\mathrm{RE}$ amorphous alloys, Zhang et al. ${ }^{9,21)}$ introduced the idea of effective atomic radii for improving Miracle's equation. The optimal glass-forming compositions of Al-Ni-RE systems were determined to be $\mathrm{Al}_{85.7} \mathrm{Ni}_{9.5} \mathrm{La}_{4.8}$ and $\mathrm{Al}_{85.5} \mathrm{Ni}_{9.5} \mathrm{RE}_{5}$ $(\mathrm{RE}=\mathrm{Y}, \mathrm{Ce}, \mathrm{Gd}, \mathrm{Dy})$. The predictions are in good agreement with the experimental results. ${ }^{9)}$

The physical and chemical properties of $\mathrm{Co}$ and $\mathrm{Ni}$ are very similar to each other. Their nominal atomic radii and Pauling electronegativities are 0.125 and $0.124 \mathrm{~nm}$, and 1.91 and 1.88 , respectively. The mixing enthalpy of liquid Al-Co $(-18.8 \mathrm{~kJ} / \mathrm{mol})$ is also very close to that of liquid $\mathrm{Al}-\mathrm{Ni}$ $(-22.3 \mathrm{~kJ} / \mathrm{mol}){ }^{31)}$ The Al-Co bond length is $0.244 \mathrm{~nm}$, shortened by $10 \%$ compared to the sum of their nominal atomic radii, and the Al-RE bond length is close to the sum of their nominal atomic radii. ${ }^{30,32)}$ Letting the effective atomic radius of $\mathrm{Co}$ be $0.101 \mathrm{~nm}$, and those of $\mathrm{Al}$ and $\mathrm{Y}$ be their nominal atomic radii $0.143 \mathrm{~nm}$ and $0.180 \mathrm{~nm}$, respectively, then the optimal glass-forming composition of $\mathrm{Al}-\mathrm{Co}-\mathrm{Y}$ alloys was calculated by the EAP model and the CSLI method to be $\mathrm{Al}_{85.5} \mathrm{Co}_{9.5} \mathrm{Y}_{5.0}$. However, as described above, the $t_{\mathrm{c}}$ of $\mathrm{Al}_{85.5} \mathrm{Co}_{9.5} \mathrm{Y}_{5}$ and its neighboring compositions is much less than that of $\mathrm{Al}_{89} \mathrm{Co}_{5.5} \mathrm{Y}_{5.5}$ and its neighbors. It seems that the CSLI model fails to predict the optimal glass forming composition of $\mathrm{Al}-\mathrm{Co}-\mathrm{Y}$ alloys.

We can find other clues from the binary phase diagrams of $\mathrm{Al}-\mathrm{Co}$ and $\mathrm{Al}-\mathrm{Ni}$ to explain the difference in the best glassforming composition between $\mathrm{Al}-\mathrm{Co}-\mathrm{Y}$ and $\mathrm{Al}-\mathrm{Ni}-\mathrm{Y}$ alloys. According to the binary phase diagrams, the intermetallic compound in the Al-rich region is monoclinic $\mathrm{Al}_{9} \mathrm{Co}_{2}$ for $\mathrm{Al}-\mathrm{Co}$ alloys but orthorhombic $\mathrm{Al}_{3} \mathrm{Ni}$ for $\mathrm{Al}-\mathrm{Ni}$ alloys. The TM-centered clusters of $\mathrm{Al}_{9} \mathrm{Co}_{2}$ and $\mathrm{Al}_{3} \mathrm{Ni}$ are shown in Fig. 6. The lattice parameters of the unit cell of monoclinic $\mathrm{Al}_{9} \mathrm{Co}_{2}$ are $\mathrm{a}=8.565 \AA, \mathrm{b}=6.290 \AA, \mathrm{c}=6.213 \AA, \alpha=90^{\circ}$, $\beta=94.760^{\circ}$ and $\gamma=90^{\circ}$, and two $\left(\mathrm{Al}_{9} \mathrm{Co}_{2}\right)$ molecules are contained in one unit cell. ${ }^{33)}$ Defining that two TM-centered clusters whose central atom distance is smaller than the double value of the maximal length of TM-Al bonds are adjacent, then it can be seen that in $\mathrm{Al}_{9} \mathrm{Co}_{2}$ a Co-centered cluster has 8 adjacent other Co-centered clusters at the distances of $4.171 \sim 4.753 \AA$ or the average distance of $4.590 \AA$. In the case of $\mathrm{Al}_{3} \mathrm{Ni}$, a Ni-centered cluster connects with 12 adjacent $\mathrm{Ni}$-centered clusters, and the distance to them changes between $3.793 \sim 4.801 \AA$ with an average value of $4.405 \AA$. This means that more Ni-centered clusters can be filled within a certain volume than Co-centered clusters, i.e. the average distance between two adjacent Co-centered clusters is larger. Reflected in the common atoms between two adjacent TM-centered clusters, as shown in Fig. 6, it can be seen that two faces and two edges of each Ni-centered cluster are shared with other Ni-centered clusters. In contrast, only one edge and no face of a Co-centered cluster are shared by the adjacent $\mathrm{Co}$-centered clusters in $\mathrm{Al}_{9} \mathrm{Co}_{2}$. That is to say, less $\mathrm{Al}$ atoms are shared between two adjacent Co-centered clusters compared with $\mathrm{Ni}$-centered clusters, and as a result the $\mathrm{Al}_{9} \mathrm{Co}_{2}$ compound contains more $\mathrm{Al}$ atoms. This can be further unraveled by the partial radial distribution functions of the TM central atoms in $\mathrm{Al}_{3} \mathrm{Ni}$ and $\mathrm{Al}_{9} \mathrm{Co}_{2}$, as illustrated in 

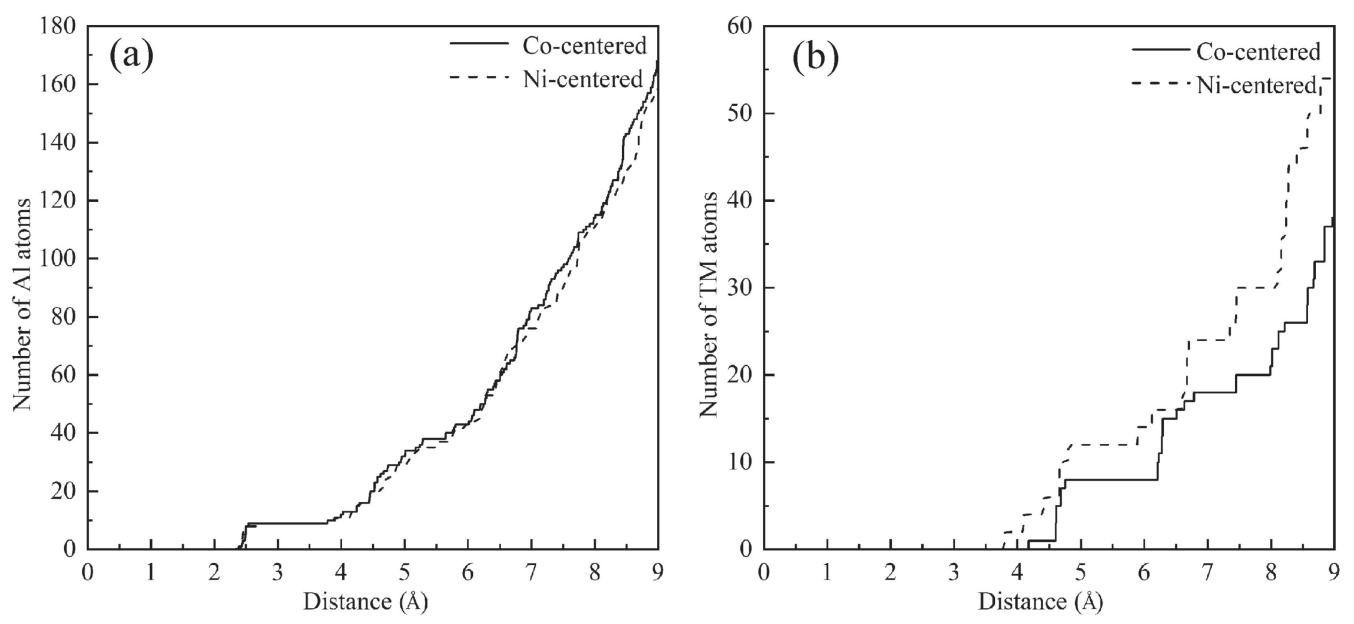

Fig. 7 The partial radial distribution function of $\mathrm{Al}_{3} \mathrm{Ni}$ and $\mathrm{Al}_{9} \mathrm{Co}_{2}$ : (a) $\mathrm{Al}$ atoms which surround the central $\mathrm{TM}$ atoms, (b) TM atoms which surround the central TM atoms.

Fig. 7. To get the RDF in Fig. 7, the structural data of $\mathrm{Al}_{3} \mathrm{Ni}$ (ICSD \#58040) and $\mathrm{Al}_{9} \mathrm{Co}_{2}$ (ICSD \#57598) were input into the software "Atom of Demeter", developed by B. Ravel, ${ }^{34)}$ to calculate the distances from the TM central atom to its surrounding atoms, and then the RDF was gained by statistically analyzing the relationship between the species and quantity of atoms and their distance to the central atom. It can be seen that a similar number of $\mathrm{Al}$ atoms surround the $\mathrm{Co}$ and $\mathrm{Ni}$ central atoms, but there are more TM atoms surrounding a central $\mathrm{TM}$ atom in $\mathrm{Al}_{3} \mathrm{Ni}$ than in $\mathrm{Al}_{9} \mathrm{Co}_{2}$. So the $\mathrm{Al}_{9} \mathrm{Co}_{2}$ phase contains relatively more $\mathrm{Al}$ atoms.

We believe that the feature for TM-centered clusters to connect each other in $\mathrm{Al}_{9} \mathrm{Co}_{2}$ and $\mathrm{Al}_{3} \mathrm{Ni}$ intermetallic compounds is also reflected in the Al-based amorphous alloys. Less common $\mathrm{Al}$ atoms are shared by two adjacent TM-centered clusters in Al-Co-Y amorphous alloys than in $\mathrm{Al}-\mathrm{Ni}-\mathrm{Y}$ amorphous alloys, meaning that more $\mathrm{Al}$ atoms are required for constructing the Co-centered clusters. Consequently the best glass former of $\mathrm{Al}-\mathrm{Co}-\mathrm{Y}$ alloys, $\mathrm{Al}_{89} \mathrm{Co}_{5.5} \mathrm{Y}_{5.5}$, contains a higher content of $\mathrm{Al}$. The present work indicates that although the coordinate number of a TM atom is mainly determined by the solute/solvent atomic radii in Al-TM-RE amorphous alloys, the packing of the TMcentered clusters is closely related with the species of the TM elements, due to which the optimal glass-forming composition changes. Since there are more $\mathrm{Al}$ atoms in $\mathrm{Al}_{89} \mathrm{Co}_{5.5} \mathrm{Y}_{5.5}$ alloy and its neighbors, only $\alpha$-Al forms as the primary phase during annealing of the amorphous alloys.

\section{Conclusion}

The optimal glass-forming composition of Al-Co-Y alloys is $\mathrm{Al}_{89} \mathrm{Co}_{5.5} \mathrm{Y}_{5.5}$, from which amorphous samples up to $405 \mu \mathrm{m}$ thickness can be produced. This composition is evidently different from $\mathrm{Al}_{85.5} \mathrm{Co}_{9.5} \mathrm{Y}_{5.0}$, the prediction by the CSLI method and the EAP model. The reason is that Co-centered clusters tend to share vertexes and edges with each other in $\mathrm{Al}-\mathrm{Co}-\mathrm{Y}$ alloys, and relatively more $\mathrm{Al}$ atoms are required. It is suggested that the species of TM atoms can greatly influence the packing of the TM-centered clusters, and therefore influence the optimal glass-forming composition. With more $\mathrm{Al}$ atoms, the amorphous alloys of $\mathrm{Al}-\mathrm{Co}-\mathrm{Y}$ around $\mathrm{Al}_{89} \mathrm{Co}_{5.5} \mathrm{Y}_{5.5}$ exhibit no glass transition during isochronal annealing, and the primary crystallization phase is constantly fcc-Al.

\section{Acknowledgments}

The authors would like to acknowledge the National Natural Science Foundation of China (Grant No. 51471108 and 51620105012) and the SJTU-UNSW cooperative Research Foundation for financial supports.

\section{REFERENCES}

1) A. Inoue, K. Ohtera, A.P. Tsai and T. Masumoto: Jpn. J. Appl. Phys. 27 (1988) L479-L482.

2) Y. He, S.J. Poon and G.J. Shiflet: Science 241 (1988) 1640-1642.

3) A. Inoue: Prog. Mater. Sci. 43 (1998) 365-520.

4) H.W. Sheng, Y.Q. Cheng, P.L. Lee, S.D. Shastri and E. Ma: Acta Mater. 56 (2008) 6264-6272.

5) N.C. Wu, D. Kan, L. Zuo and J.Q. Wang: Intermetallics 39 (2013) $1-4$.

6) Y.H. Kim, A. Inoue and T. Masumoto: Mater. Trans., JIM 31 (1990) 747-749.

7) H. Yang, J.Q. Wang and Y. Li: Philos. Mag. 87 (2007) 4211-4228.

8) Y.H. Kim, A. Inoue and T. Masumoto: Mater. Trans., JIM 32 (1991) 599-608.

9) Z. Zhang, X.Z. Xiong, W. Zhou, X. Lin, A. Inoue and J.F. Li: Intermetallics 42 (2013) 23-31.

10) R.S. Maurya and T. Laha: J. Mater. Sci. Technol. 31 (2015) 1118-1124.

11) A. Inoue: Sci. Rep. Res. Inst. Tokohu. Univ. A Phys. Chem. Metall. 42 (1996) 1-11.

12) B.J. Yang, J.H. Yao, J. Zhang, H.W. Yang, J.Q. Wang and E. Ma: Scr. Mater. 61 (2009) 423-426.

13) B.J. Yang, J.H. Yao, Y.S. Chao, J.Q. Wang and E. Ma: Philos. Mag. 90 (2010) 3215-3231.

14) N.C. Wu, L. Zuo, J.Q. Wang and E. Ma: Acta Mater. 108 (2016) 143151.

15) J.P. Liao, B.J. Yang, Y. Zhang, W.Y. Lu, X.J. Gu and J.Q. Wang: Mater. Des. 88 (2015) 222-226.

16) C. Suryanarayana and A. Inoue: Bulk Metallic Glasses, (CRC Press, Canada, 2010) pp. 34-38.

17) A. Takeuchi, K. Amiya, T. Wada, K. Yubuta, W. Zhang and A. Makino: Mater. Trans. 55 (2014) 165-170.

18) O. Haruyama, K. Yoshikawa, Y. Yamazaki, Y. Yokoyama and T. Egami: Mater. Trans. 56 (2015) 648-654. 
19) D.B. Miracle, W.S. Sanders and O.N. Senkov: Philos. Mag. 83 (2003) 2409-2428.

20) C.S. Ma, J. Zhang, W.L. Hou, X.C. Chang and J.Q. Wang: Philos. Mag. Lett. 88 (2008) 599-605.

21) Z. Zhang, W. Zhou, X.Z. Xiong, L.T. Kong and J.F. Li: Intermetallics 24 (2012) 1-6.

22) H. Yang, J.Q. Wang and Y. Li: J. Non-Cryst. Solids 354 (2008) 34733479.

23) P. Dong, J. Zhang, W. Hou, X. Chang, J. Wang and M. Quan: J. Mater. Sci. Technol. 24 (2008) 161-164.

24) D. Ma and Y.A. Chang: Acta Mater. 54 (2006) 1927-1934.

25) D. Xu, B. Lohwongwatana, G. Duan, W.L. Johnson and C. Garland: Acta Mater. 52 (2004) 2621-2624.

26) L. Xia, D. Ding, S.T. Shan and Y.D. Dong: J. Phys.: Condens. Matter
18 (2006) 3543-3548.

27) D. Turnbull: Contemp. Phys. 10 (1969) 473-488.

28) R.D. Sá Lisboa, C. Bolfarini, F.W.J. Botta and C.S. Kiminami: Appl. Phys. Lett. 86 (2005) 211904.

29) A.N. Mansour, A. Marcelli, G. Cibin, G. Yalovega, T. Sevastyanova and A.V. Soldatov: Phys. Rev. B 65 (2002) 134207.

30) A.N. Mansour, C.P. Wong and R.A. Brizzolara: Phys. Rev. B 50 (1994) 12401-12412.

31) A. Takeuchi and A. Inoue: Intermetallics 18 (2010) 1779-1789.

32) W. Zalewski, J. Antonowicz, R. Bacewicz and J. Latuch: J. Alloys Compd. 468 (2009) 40-46.

33) A. Douglas: Acta Crystallogr. 3 (1950) 19-24.

34) B. Ravel and M. Newville: J. Synchrotron Radiat. 12 (2005) 537-541. 